\title{
ANÁLISE DA FRAGILIDADE AMBIENTAL NA BACIA HIDROGRÁFICA DO RIBEIRÃO DOURADINHO, SUDOESTE DE GOIÁS
}

Wellmo dos Santos Alves ${ }^{1}$, Alécio Perini Martins², Ana Karoline Ferreira dos Santos ${ }^{3}$, Derick Martins Borges de Moura ${ }^{4}$

(1 - Universidade Federal de Goiás, Regional Jataí, Doutorando em Geografia wellmoagro2@gmail.com; 2 - Universidade Federal de Goiás, Regional Jataí Docente do Programa de Pós-Graduação em Geografia, alecioperini@yahoo.com.br; 3 - Universidade Federal de Goiás, Regional Jataí, Mestranda em Geografia, karoljti.santos@gmail.com; 4 Universidade Federal de Goiás, Instituto de Estudos Socioambientais, Doutorando em Geografia, derickmartins@ @otmail.com).

Resumo: Compreender a fragilidade ambiental de uma bacia hidrográfica é essencial para avaliar como as características físicas e antrópicas estão interferindo no equilíbrio dinâmico de seu ambiente. Diante disso, esse trabalho objetivou analisar a fragilidade ambiental da bacia hidrográfica do ribeirão Douradinho (GO), sub-bacia da bacia hidrográfica do rio São Tomás, inserida no Sudoeste de Goiás, microrregião destaque na produção agropecuária. $\mathrm{O}$ estudo teve como base a metodologia proposta por Ross (1994), que usa como indicadores de fragilidade ambiental a declividade, tipos de solos, erosividade, uso da terra e cobertura vegetal. Os produtos cartográficos foram elaborados a partir de dados de sensoriamento remoto e técnica de geoprocessamento. Como resultados foram verificadas áreas com classes de fragilidade potencial:muito baixa $(28,68 \%)$ e baixa $(71,32 \%)$; e classes de fragilidade emergente:muito baixa $(3,19 \%)$, baixa $(42,42 \%)$ e média $(54,38 \%)$. Na área de média fragilidade emergente, associada ao manejo inadequado do solo, foi constatada erosão laminar, ou seja, perda de solo, causando prejuízos ambientais e econômicos. Nota-se a necessidade de implementação de técnicas de manejo e conservação do solo adequadas dentro da bacia hidrográfica, protegendo os recursos naturais e promovendo a qualidade de vida.

Palavras-chave: Ação antrópica, Análise ambiental, Geotecnologias, Gestão ambiental.

\footnotetext{
Artigo recebido para publicação em 05 de julho de 2017

Artigo aprovado para publicação em 21 de Dezembro de 2017
} 


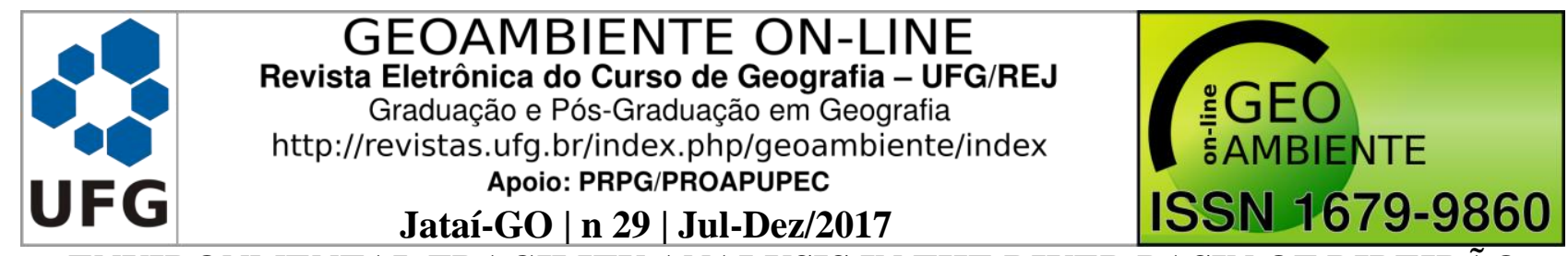

ENVIRONMENTAL FRAGILITY ANALYSIS IN THE RIVER BASIN OF RIBEIRÃO DOURADINHO, SOUTH-WEST OF GOIÁS (BRAZIL)

Abstract: Understanding the environmental fragility of a river basin is essential to evaluate how the physical and anthropic characteristics are interfering in the dynamic balance of its environment. Therefore, this paper aimed to analyze the environmental fragility of the river basin of ribeirão Douradinho (GO), sub-basin of the river basin of rio São Tomás, inserted in the South-west of Goiás state, an important microregion in the farming production. The study had as a basis the methodology proposed by Ross (1994), which uses as environmental fragility indicators the declivity, soil types, erosivity, land use and vegetation coverage. The cartographic products were elaborated from remote sensing data and geoprocessing techniques. As results were verified areas with classes of potential fragility: very low $(28,68 \%)$ and low $(71,32 \%)$; and emerging fragility classes: very low $(3,19 \%)$, low $(42,42 \%)$ and average $(54,38 \%)$. In the area of average emerging fragility, associated to the inappropriate management of the soil, laminar erosion was verified, in other words, soil loss, causing environmental and economic losses. It's possible to notice the need of implementation of management and proper soil conservation techniques within the river basin, protecting the natural resources and promoting the quality of life.

Keywords: Anthropic action, Environmental Analysis, Geotechnologies, Environmental management.

\section{ANÁLISIS DE LA FRAGILIDAD AMBIENTAL EN LA CUENCA HIDROGRÁFICA DEL RIBEIRÃO DOURADINHO, SUDOESTE DE GOIÁS}

Resumen: Comprender la fragilidad ambiental de una cuenca hidrográfica es esencial para evaluar cómo las características físicas y antrópicas están interfiriendo en el equilibrio dinámico de su ambiente. En este sentido, este trabajo objetivó analizar la fragilidad ambiental de la cuenca hidrográfica del ribeirão Douradinho (GO), subcuenca de la cuenca hidrográfica del Río Santo Tomás, inserta en el Sudoeste de Goiás, microrregión destaque en la producción agropecuaria. El estudio tuvo como base la metodología propuesta por Ross (1994) que utiliza como indicadores de fragilidad ambiental la declividad, tipos de suelos, erosividad, uso de la tierra y cobertura vegetal. Los productos cartográficos fueron elaborados a partir de datos de sensorización remota y técnicas de geoprocesamiento. Como resultados se verificaron áreas con clases de fragilidad potencial: muy baja $(28,68 \%)$ y $(71,32 \%)$; y las clases de fragilidad emergente: muy baja $(3,19 \%)$, baja $(42,42 \%)$ y media $(54,38 \%)$. En el 
área de media fragilidad emergente, asociada al manejo inadecuado del suelo, se constató erosión laminar, es decir, pérdida de suelo, causando daños ambientales y económicos. Se observa la necesidad de implementar técnicas de manejo y conservación del suelo adecuados dentro de la cuenca hidrográfica, protegiendo los recursos naturales y promoviendo la calidad de vida.

Palabras clave: Acción antrópica, Análisis ambiental, Geotecnologías, Gestión ambiental.

\section{Introdução}

A fragilidade envolve a vulnerabilidade do espaço com relação as suas características físicas, sociais e econômicas. É uma das principais formas de identificar como um espaço geográfico se encontra em relação aos seus aspectos físicos, devido fornecer importantes informações sobre a declividade, o solo, a erosividade, uso da terra e cobertura vegetal, dentre outras características de um espaço geográfico, sendo essencial para o planejamento ambiental de uma área de interesse.

Estudos com a temática de fragilidade ambiental têm como um de seus precursores Tricart (1977), o qual desenvolveu o conceito de ecodinâmica, que tem como princípio básico o meio natural e suas trocas de energia dinâmica, sendo o homem um dos agentes desse processo. Para este autor, quando os ambientes estão em equilíbrio dinâmico são estáveis, e quando se encontram em desequilíbrio, são instáveis.

Ross (1994) inseriu novos critérios para o conceito de unidades ecodinâmicas, acrescentando para unidades ecodinâmicas estáveis a denominação fragilidade potencial, e para unidades instáveis, o termo de fragilidade emergente, classificando cada uma dessas duas unidades em cinco (5) níveis hierárquicos de fragilidade, que varia de muito fraca (ou muito baixa), fraca (ou baixa), média, forte (ou alta) e muito forte (ou muito alta).

Para Tamanini (2008), a fragilidade ambiental diz respeito a um espaço sofrer qualquer tipo de dano relacionado com fatores de desequilíbrio de ordem natural, expresso pela própria dinâmica do ambiente, e por atividades antrópicas.

Em estudos sobre fragilidade ambiental existem dois termos importantes; fragilidade potencial e fragilidade emergente (KAWAKUBO et al., 2005). O primeiro termo representa os graus de fragilidade, sob a ação dos processos morfogenéticos atuantes na paisagem, resultantes da correlação de alguns dos componentes físico-naturais da paisagem (declividade 
do terreno, tipo de solos e erosividade das chuvas), e o segundo, indica como as formas de uso da terra e cobertura vegetal interferem na dinâmica natural (ROSS, 1994).

Dentre os principais recursos para auxiliar no monitoramento da fragilidade ambiental, encontram-se dados de sensoriamento remoto e técnicas de geoprocessamento, instrumentos, segundo Rosa (2009), poderosos no levantamento, mapeamento e monitoramento dos recursos naturais.

Atualmente existem diversos estudos voltados para identificar a fragilidade ambiental de uma área, como os realizados por Queiroz Júnior (2015) para a bacia hidrográfica da Usina Hidrelétrica Foz do Rio Claro (GO), no qual foi constatado que a agricultura foi a ação antrópica que mais influenciou na alteração das classes de fragilidade ambiental. Já em pesquisas desenvolvidas por Cabral et al., (2011) para a área da bacia hidrográfica do rio Doce (GO) foi verificado o predomínio da classe média na fragilidade emergente, sendo um dos fatores para a ocorrência dessa classe a forma de uso da terra vinculada às atividades de agricultura mecanizada com o cultivo de soja e milho, sendo que, anteriormente, esses espaços eram principalmente de pastagens e vegetação natural.

Nesse contexto,realizou-se o presente estudo, que tem como objetivo principal analisar os níveis de fragilidade ambiental na bacia hidrográfica do ribeirão Douradinho (GO), um dos importantes afluentes do rio São Tomás, sendo este a principal fonte de abastecimento de água da população urbana do município de Rio Verde (GO) e de Santa Helena de Goiás (GO), além de ser fonte de água de diversas atividades agropecuárias (irrigação, criação de gado, granjas de médio e grande porte de aves e suínos), de agroindústrias (como a BRF unidade de Rio Verde, uma das maiores agroindústrias do mundo) e de outros usos.

\section{Material e Método}

As bases de dados geográficos foram compiladas do Google Earth Pro, Sistema Estadual de Geoinformação de Goiás (SIEG) e United States Geological Survey (USGS). E os dados de precipitação foram obtidos na página do Banco de Dados Meteorológicos para Ensino e Pesquisa (BDMEP).

O processamento digital das bases de dados geográficos foi realizados na interface gráfica doArcGIS $10.1^{\circledR}$, licenciado para o Laboratório de Geoinformação da Universidade Federal de Goiás (UFG)/Regional de Jataí.

\section{1Área de estudo}


O presente trabalho foi desenvolvido para estudo de dados na bacia hidrográfica do ribeirão Douradinho (Figura 1) com nascente no município de Rio Verde (GO), no local com as coordenadas geográficas $50^{\circ} 51^{\prime} 26,239^{\prime \prime} \mathrm{W} / 17^{\circ} 47^{\prime} 3,553^{\prime \prime} \mathrm{S}$ e altitude de $780 \mathrm{~m}$, e foz na margem esquerda do rio São Tomás, no município de Santa Helena de Goiás (GO), no local com as coordenadas geográficas $50^{\circ} 40^{\prime} 8,355^{\prime \prime} \mathrm{W} / 17^{\circ} 51^{\prime} 13,306 " \mathrm{~S}$ e altitude de $545 \mathrm{~m}$. Inseridos no Sudoeste de Goiás, na bacia do rio Paranaíba, esses municípios apresentam economia baseada na agropecuária.

Figura 1- Localização da bacia hidrográfica do ribeirão Douradinho, Sudoeste de Goiás

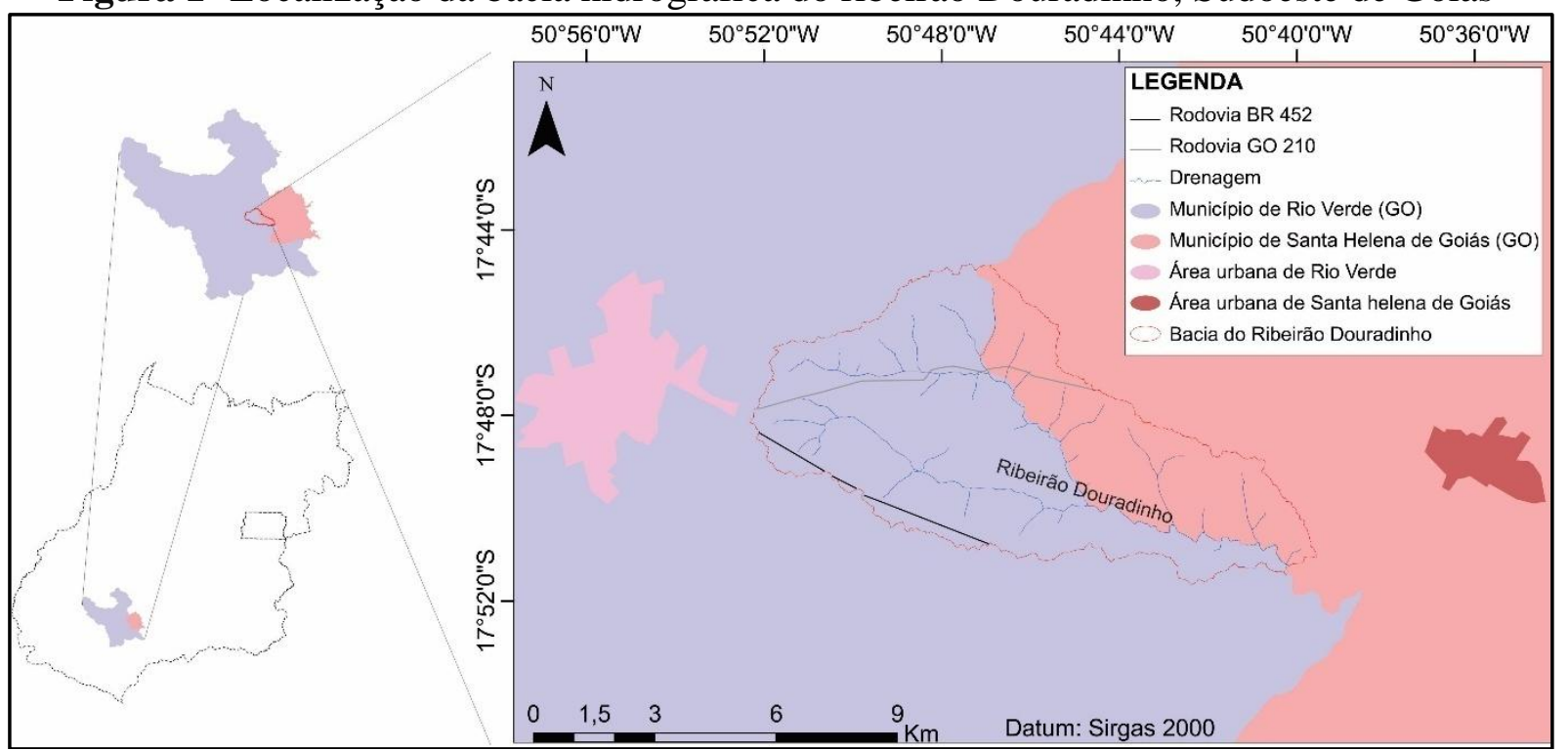

Fonte: Elaborado pelos autores a partir de bases de dados geográficos disponibilizadas pelo SIEG (2017).

Conforme a classificação de Köppen-Geiger, o clima da região se enquadra no tipo AW, caracterizado por climas úmidos tropicais, com duas estações bem definidas: seca no inverno e úmida no verão (PEEL et al., 2007).

\subsection{Bases de dados}

A partir das bases de dados geográficos seguintes foram elaborados os mapas de declividade, solos, arquivo shapefile ( $(\mathrm{h} p)$ para atribuição do valor numérico relacionado à erosividade, uso da terra e cobertura vegetal:

$\checkmark$ Imagem Shuttle Radar TopographyMission (SRTM), com resolução espacial de 30 m x 30 m, gerada pela cooperação entre NationalAeronauticsand Space Administration (NASA) e a NationalImageryandMappingAgency (NIMA), do DOD (Departamento de Defesa) dos Estados Unidos da América e das agências espaciais da Alemanha e da Itália; obtida 
através de arranjo projetado para coletar medidas tridimensionais da superfície terrestre através de interferometria, a bordo do ônibus espacial Endeavour, entre o período de 11 a 22 de fevereiro de 2000; disponibilizada pelo USGS (2016);

Mapa de Solos do Plano Diretor da Bacia do Rio Paranaíba, na escala 1:250.000, formato shapefile (shp), geração 01 de março de 2005, gerado pela Universidade Federal de Viçosa (UFV)/Fundação Rural Minas (Ruralminas); modelagem, alimentação do SIG e edição das cartas pela Superintendência de Geologia e Mineração/Secretaria Estadual de Indústria e Comércio (SGM/SIC); disponibilizado pelo SIEG (2016);

$\checkmark$ Imagem de 2016 do Satélite Landsat 8órbita/ponto 223/72, com resolução máxima de 4.800 pixels, baixada por meio do Hipermapa Google Earth Pro.

\subsection{Processamento dos dados}

A partir da imagem SRTM foram geradas curvas de nível com equidistância de $5 \mathrm{~m}$, com uso da ferramenta contour. A partir dessas curvas foi delimitada a área da bacia hidrográfica do ribeirão Douradinho, desenhada a partir da seção fluvial do exutório, ou seja, do ponto mais baixo, em direção ao divisor de água, gerando-se um arquivo shp.

O shp da delimitação da área de estudo foi utilizado para extrair as bases delimitadas da bacia hidrográfica das bases geográficas maiores, usando a ferramenta Extract by Masc, no caso das bases de dados em formato raster, e com o uso da ferramenta clip, no caso das bases de dados em formato shp.

Utilizando-se o SRTM com delimitação da bacia hidrográfica foi gerado o mapa de declividade, com o uso da ferramenta Slope, com reclassificação por meio da ferramenta Reclassify. A declividade foi realizada de acordo com a proposta da Embrapa (2013), que classifica o relevo entre plano (0 a 3\%) a forte montanhoso (>75\%), ver Quadro 1, sendo mais adequada para a região.

Quadro 1 - Níveis de Fragilidade por classe de declividade

\begin{tabular}{|c|c|c|}
\hline Classe de Fragilidade & Declividade (\%) & Descrição \\
\hline Muito baixa & $0-3$ & Plano \\
\hline Baixa & $3-8$ & Suave ondulado \\
\hline Média & $8-20$ & Ondulado \\
\hline Alta & $20-45$ & Forte ondulado \\
\hline \multirow{2}{*}{ Muito alta } & $45-75$ & Montanhoso \\
\hline & $>75$ & Forte montanhoso \\
\cline { 2 - 3 }
\end{tabular}

Fonte: Adaptado de Ross (1994) e da Embrapa (2013). 
Com o uso do shp da delimitação da área de estudo e da ferramenta Clip, foi extraído do Mapa de Solos do Plano Diretor da Bacia do Rio Paranaíba a base menor correspondente aos solos da bacia hidrográfica.

Segundo a proposto de Ross (1994), a fragilidade ambiental varia conforme o tipo de solo, ver Quadro 2.

Quadro 2 - Classes de fragilidade dos tipos de solo

\begin{tabular}{|c|c|}
\hline Classe de fragilidade & Tipo de solo \\
\hline Muito baixa & Latossolo Vermelho \\
\hline Baixa & Latossolo Amarelo \\
\hline Média & Latossolo Bruno, Argissolo Vermelho. \\
\hline Alta & Argissolo Vermelho-amarelo, Cambissolos. \\
\hline Muito alta & Espodossolos, NeossolosLitólicos eNeossolosQuartzarênicos. \\
\hline
\end{tabular}

Fonte: Adaptado de Ross (1994) e da Embrapa (2013).

Para obter o valor da erosividade da chuva (fator $R$ ) utilizou-se a Equação 1 conforme Wischmeier e Smith (1978), com adaptação para as condições brasileiras por Lombardi e Moldenhauer (1977) apud Bertoni e Lombardi Neto (1999):

$$
E I 30=67,355\left(r^{2} / P\right)^{0,85}
$$

Sendo que: EI30é a média mensal do índice de erosividade em MJ.mm/(ha.h); r, a média dos totais mensais de precipitação em mm; e P, a média dos totais anuais de precipitação em mm.

Com o propósito de classificar a bacia hidrográfica quanto à erosividade da chuva, foi realizada a conversão do valor MJ.mm.há ${ }^{-1} \cdot \mathrm{h}^{-1} \cdot$ ano $^{-1}$ para tn.mm.ha ${ }^{-1} \cdot$ ano $^{-1}$, ou seja, o valor inicial foi dividido por 9,81, conforme observado em Cabral et al. (2011). Em seguida, os valores de erosividade foram comparados com as classes propostas por Carvalho (1994), conforme o Quadro 3.

Quadro 3 - Classes de erosividade da chuva (média anual)

\begin{tabular}{|c|c|}
\hline Classes de erosividade & Erosividade (tn.mm.ha ${ }^{-1} \cdot$ ano $^{-1}$ ) \\
\hline Muito baixa & $\mathrm{R}<250$ \\
\hline Baixa & $250<\mathrm{R}<500$ \\
\hline Média & $500<\mathrm{R}<750$ \\
\hline Alta & $750<\mathrm{R}<1000$ \\
\hline Muito alta & $\mathrm{R}>1000$ \\
\hline
\end{tabular}

Fonte: Carvalho (1994). 


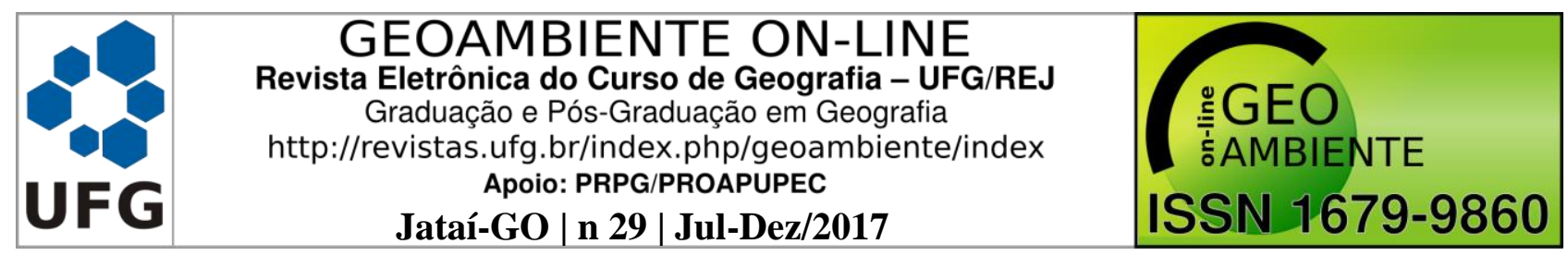

De acordo com a proposta de Carvalho (1994), a erosividade varia de muita baixa (< 250) a muito alta (1000), sendo que a mesma é influenciada pela intensidade da precipitação pluviométrica.

A imagem do Google Earth Pro foi georreferenciada no ArcGIS $10.1^{\circledR}$ com o uso da ferramenta Georreferencing, em seguida foi classificada através da técnica de classificação digital supervisionada, com o uso da ferramenta Interactive Supervised Classification, embasando sena "Chave de Interpretação" de imagens do Google Earth proposta por Ayach et al. (2012) e em levantamentos de campo realizados para coleta de informações, seleção e georreferenciamento de áreas conhecidas, visando que o algoritmo classificador do software SIG utilizado operasse baseado na distribuição de probabilidade de cada classe estabelecida. As classes estabelecidas foram: agricultura, pastagem, vegetação do Cerrado (área de preservação permanente e reserva legal), solo úmido/veredas, vias pavimentadas, lagos e granjas. Posteriormente a imagem foi reclassificada com o uso da ferramenta Reclassify, convertida para polígono, com o uso da ferramenta Raster to Polygon, tornando-se possível quantificar os diferentes usos da terra e cobertura vegetal na Attribute Table.

Nos levantamentos de campo, com uso de uma câmera digital, modelo Nikon D5100, foram tiradas fotografias visando validar e ilustrar o mapa de solos, uso da terra e cobertura vegetal. Todas as fotografias foram georreferenciadas com um GPS modelo Garmin GPSMAP 62sc.

Com o uso do Software QGIS 2.16 e seu complemento Acuracy, foi realizado o cruzamento do mapa de uso da terra e cobertura vegetal e amostras kappa ou amostras de validação (levantadas em campo e com uso do Google Earth Pro), visando à obtenção da matriz de confusão.

Em planilha do Excel 2013, a partir da matriz de confusão obtida, foi calculado o Índice Kappa, que é um teste estatístico aplicado aos resultados da classificação do uso da terra e cobertura vegetal, levando em consideração toda a matriz de confusão no seu cálculo, até mesmo os elementos de fora da diagonal principal.

O cálculo do índice Kappa foi realizado com uso da Equação 2(SIMÕES, 2001):

$\mathrm{K}=\left(\mathrm{n} * \sum_{\mathrm{i}=1}^{\mathrm{c}} \mathrm{X}_{\mathrm{ij}}-\sum_{\mathrm{j}=1}^{\mathrm{c}} \mathrm{X}_{1+} * \mathrm{X}_{+1}\right) /\left(\mathrm{n}^{2}-\sum_{\mathrm{j}=1}^{\mathrm{c}} \mathrm{X}_{1+} * \mathrm{X}_{+1}\right)$

Em que: K é uma estimativa do coeficiente Kappa; n, o número total de amostras; c, o número total de classes; $\mathrm{x}_{\mathrm{ij}}$, valor na linha i e coluna $\mathrm{j}$, ou seja, o valor da diagonal da matriz de confusão, de forma descendente; $\mathrm{x}_{\mathrm{i}+,} \mathrm{a}$ soma da linha $\mathrm{i}$; e $\mathrm{x}_{+\mathrm{j}}$, a soma da coluna $\mathrm{j}$ da matriz de confusão. 
Com base no Quadro 4 definiu-se a qualidade da classificação da imagem (LANDIS; KOCH, 1977).

Quadro 4-Qualidade da classificação conforme intervalos do Índice Kappa

\begin{tabular}{|c|c|}
\hline Valor Kappa & Qualidade da classificação \\
\hline$<0,00$ & Péssima \\
\hline $0,00-0,20$ & Ruim \\
\hline $0,20-0,40$ & Razoável \\
\hline $0,40-0,60$ & Boa \\
\hline $0,60-0,80$ & Muito Boa \\
\hline $0,80-1,00$ & Excelente \\
\hline
\end{tabular}

Fonte: Landis e Koch (1977).

Os produtos cartográficos da fragilidade ambiental da bacia hidrográfica do ribeirão Douradinho foram gerados com base na metodologia de Ross (1994), que classifica os ambientes em fragilidade potencial e fragilidade emergente em cinco níveis, que varia de muito baixa (muito fraca), baixa (fraca), média, forte (alta) a muito forte (muito alta), ver Quadro 5.

Quadro 5 - Graus de fragilidade e proteção

\begin{tabular}{|c|c|c|c|}
\hline Cor & Graus de fragilidade & Grau de proteção & Valor numérico \\
\hline & Muito baixa & Muito alta & 1 \\
\hline & Baixa & Alta & 2 \\
\hline & Média & Média & 3 \\
\hline & Alta & Baixa & 4 \\
\hline & Muito alta & Muito baixa & 5 \\
\hline
\end{tabular}

Fonte: Adaptado de Ross (1994).

Para a geração do mapa e análise da fragilidade potencial foram utilizados o mapa de declividade, mapa de solos e mapa de erosividade reclassificados, conforme características apresentadas no Quadro 1, Quadro 2 e Quadro 3, respectivamente, e valor numérico (Quadro 5). E para a geração do mapa da fragilidade emergente foi realizado o cruzamento dos mapas de fragilidade potencial e uso da terra e cobertura vegetal, sendo este reclassificado conforme as categorias observadas e valor numérico para o grau de proteção apresentado Quadro 5.

Os mapas foram cruzados na ferramenta Raster Calculator utilizando a Equação 3 para gerar o mapa de fragilidade potencial, e a Equação 4, para o mapa de fragilidade emergente: 


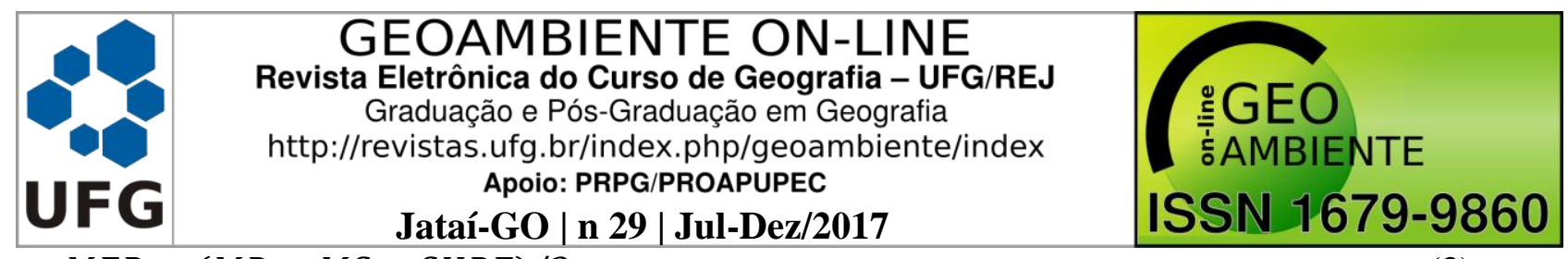

$M F P=(M D+M S+S H P E) / 3$

Sendo que: MFP é a o mapa de fragilidade potencial; MD, o mapa de declividade; MS, o mapa de solos; e SHPE, o arquivo shp contendo o valor atribuído à erosividade.

$M F E=(M F P+M U T C V) / 2$

Sendo que: MFE é o mapa de fragilidade emergente; e MUTCV, o mapa de uso da terra e cobertura vegetal.

Obtidos os mapas de fragilidade potencial e emergente, estes foram convertidos para polígonos, com o uso da ferramenta Raster to Polygon, para tornar possível a obtenção, na Attribute Table, da área correspondente a cada classe de fragilidade.

\section{Resultados e discussão}

Na Tabela 1 e Figura 2 é destacada a declividade na bacia hidrográfica do ribeirão Douradinho, que é caracterizada por relevo predominantemente plano (0-3\%) e suave ondulando (3-8\%), o que classifica a bacia hidrográfica como propícia para desenvolvimento de atividades agrícolas, desde que com planejamento ambiental e agronômico adequados, principalmente nas áreas com maior declividade.

Tabela 1 - Classes de declividade (S) em \% e respectiva fragilidade ambiental na bacia hidrográfica do ribeirão Douradinho, Sudoeste de Goiás

\begin{tabular}{cccc}
\hline S $(\%)$ & ha & $\%$ & Fragilidade \\
\hline $0-3$ & 4.187 & 28,03 & Muito baixa \\
$3-8$ & 8.999 & 60,25 & Baixa \\
$8-20$ & 1.683 & 11,27 & Média \\
$20-45$ & 65 & 0,44 & Alta \\
$>45$ & 1 & 0,01 & Muito alta \\
\hline Total & 14935 & 100 & -
\end{tabular}

Fonte: Adaptado de Ross (1994) e da Embrapa (2013). 
Figura 2- Declividade na bacia hidrográfica do ribeirão Douradinho, Sudoeste de Goiás

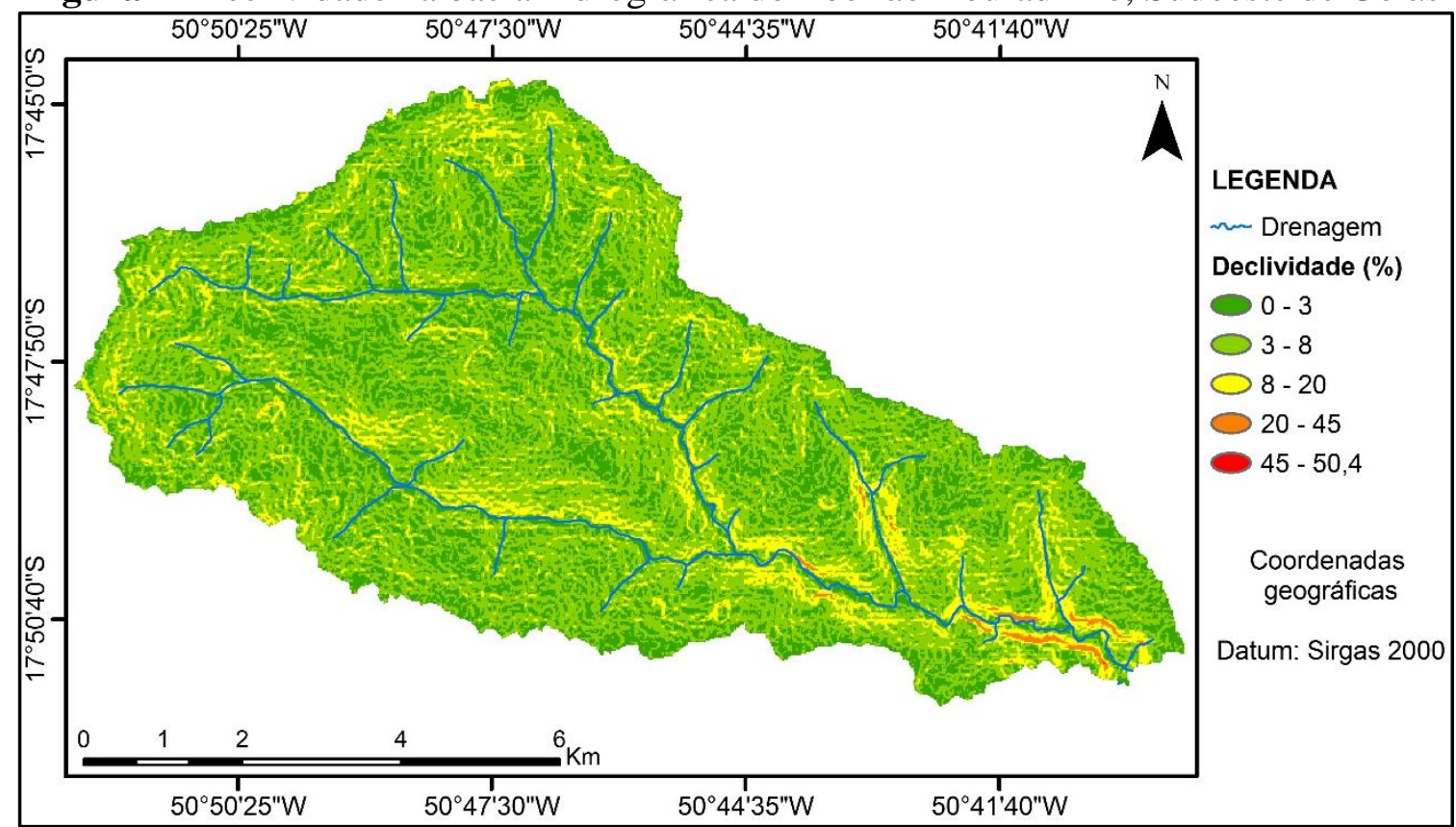

Fonte: Elaborado pelos autores a partir do SRTM disponibilizado pelo USGS (2017).

Observou-se predominância de Latossolos, sendo a maior área de Latossolo Vermelho Distrófico, textura muito argilosa ou argilosa (LVd3), 84,07\%, e Latossolo Vermelho Eutrófico, textura média (LVe2), 15,93\%(Tabela 2; Figura 3).

Os Latossolos, durante sua formação, passam por intensos processos de intemperismo, são profundos e com boa capacidade de drenagem, no entanto apresentam características físicas susceptiveís a erosão quando descobertos (EMBRAPA, 2013).

No município de Rio Verde (GO), a precipitação anual entre os anos de 1996 a 2016 foi de 1612,19 mm, e a média dos totais mensais, de 134,59 mm. Os maiores níveis pluviométricos ocorrem nos meses de outubro a abril, e os menores, de maio a setembro, conforme dados observados na estação 83470 de Rio Verde (GO) obtidos no BDMEP (2017). Na Figura 4 são observadas as médias mensais.

Tabela 2 - Classes de solo e respectiva fragilidade ambiental na bacia hidrográfica do ribeirão Douradinho, Sudoeste de Goiás

\begin{tabular}{ccccc}
\hline & Classe de solos & Ha & $\%$ & Fragilidade \\
\hline Símbolo & Associação de solos & & & \\
\hline LVd3 & Latossolos Vermelhos Distróficos, textura muito & 12.556 & 84,07 & $\begin{array}{c}\text { Muito } \\
\text { baixa }\end{array}$ \\
LVe2 & Latossolos Vermelhosa ou argilosa. & 2.379 & 15,93 & Eutróficos, textura média. \\
\hline Total & - & 14.935 & 100 & - \\
\hline
\end{tabular}

Fonte: Adaptado de Ross (1994) e do SIEG (2017). 
Figura 3 - Tipos de solos na bacia hidrográfica do ribeirão Douradinho, Sudoeste de Goiás

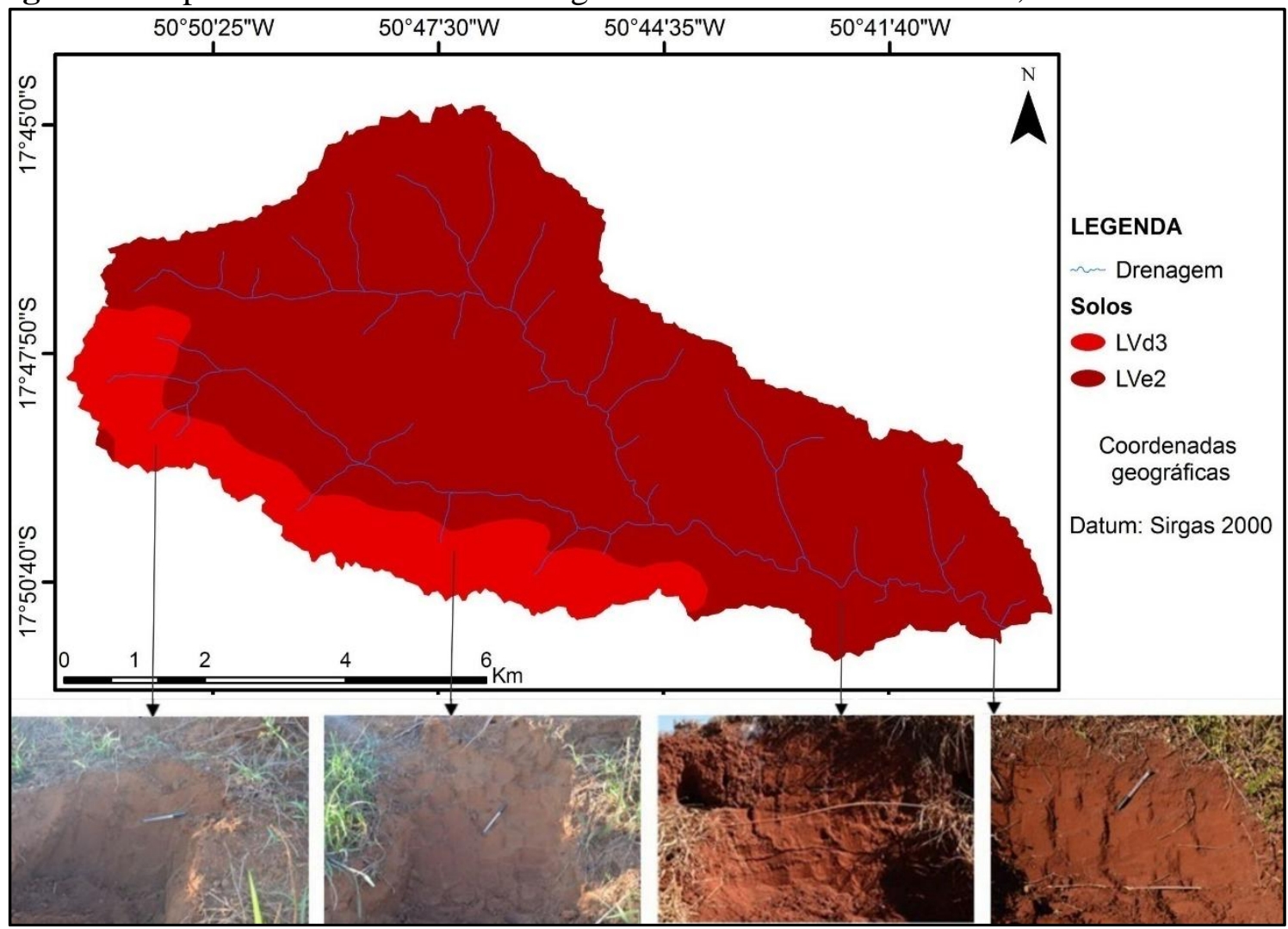

Fonte: Elaborado pelos autores a partir do Mapa de Solos do Plano Diretor da Bacia Hidrográfica do Rio Paranaíba.

Figura 4 - Gráfico da média mensal de precipitação (mm) de janeiro de 1996 a dezembro de 2016, no município de Rio Verde (GO)

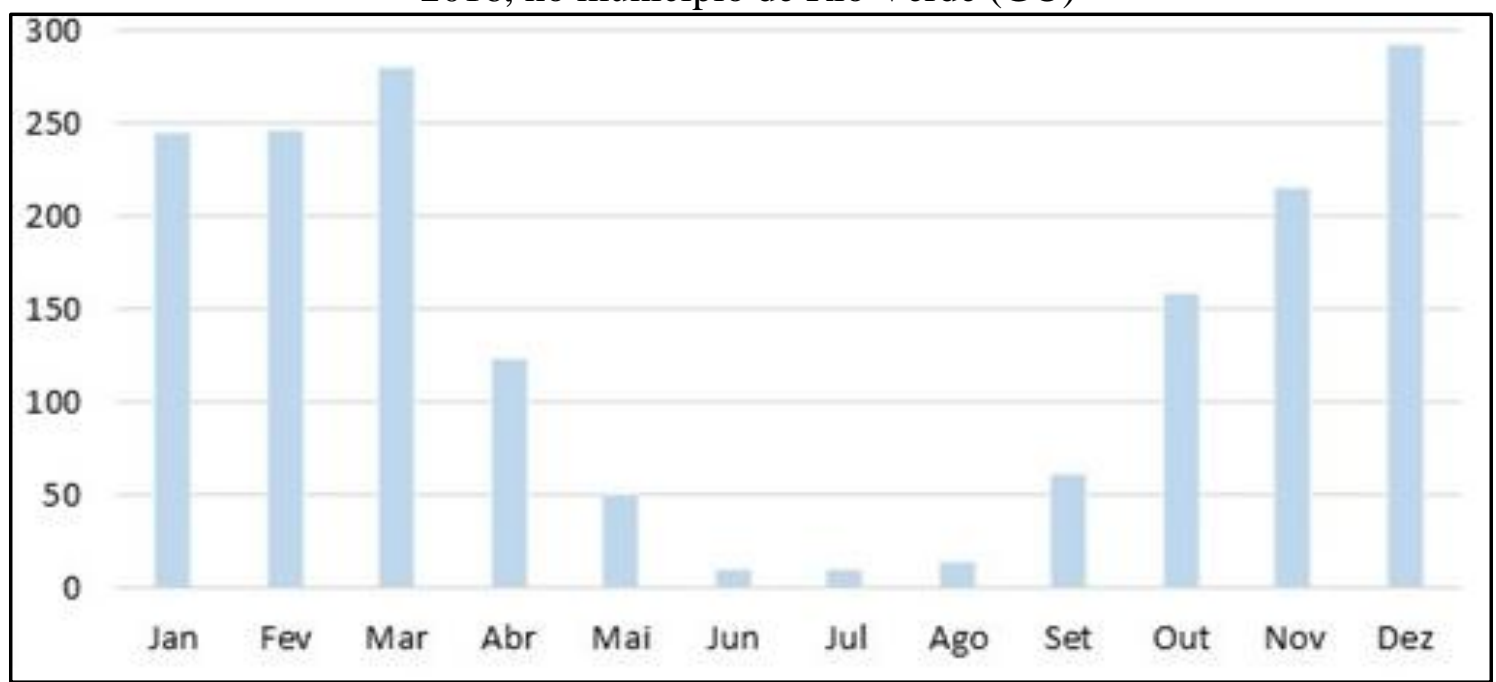

Fonte: Elaborado pelos autores a partir de dados cedidos pelo BDMEP (2017). 


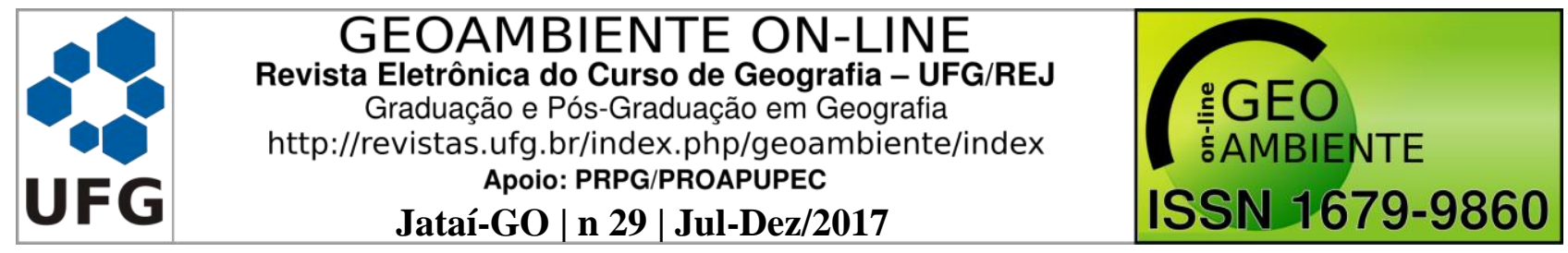

Para a erosividade na área da bacia hidrográfica,proporcionada pelos volumes de precipitação, verificou-se o valor de 697,62 tn.ha ${ }^{-1} \cdot$ ano $^{-1}$, sendo, conforme a proposta de Carvalho (1994), classificada como de médio risco de erosividade (Quadro 5).

$\mathrm{Na}$ Tabela 3 são apresentadas as categorias do uso da terra e cobertura vegetal na bacia hidrográfica do ribeirão Douradinho, sendo a maior área de culturas anuais(72,57\%), considerada de baixa proteção, seguida de pastagem $(13,10 \%)$, média proteção, vegetação nativa do Cerrado (10,57\%), constituído principalmente de área de preservação permanente e reserva legal, alta proteção, Campo limpo/solos úmidos (2,43\%), muito baixa proteção, e outras áreas menos representativas (rodovias, represas, ferrovia e granjas).A espacialização do uso da terra e cobertura vegetal na área de estudo pode ser observada na Figura 5.

Foi obtido resultado de 0,86 para o Índice Kappa na avaliação da qualidade da classificação do mapa de uso da terra e cobertura vegetal no ano de 2016, consistindo excelente grau de aceitação desse produto cartográfico (LANDIS; KOCH, 1977; CONGALTON; GREEN, 2009).

A bacia hidrográfica do ribeirão Douradinho, assim como a área da bacia hidrográfica do ribeirão das Abóboras, localizada em Rio Verde (GO), apresenta uso da terra predominante para atividades vinculadas agricultura e pastagem, sendo que as áreas de vegetação natural estão sendo substituídas por vegetação agrícola (ALVES et al. 2016).

Tabela 3 - Categorias de uso da terra e cobertura vegetal e respectivo grau de proteção na bacia hidrográfica do ribeirão Douradinho, Sudoeste de Goiás

\begin{tabular}{cccc}
\hline Categorias & ha & $\%$ & Proteção \\
\hline Culturas anuais & 10.839 & 72,57 & Baixa \\
Pastagens & 1.954 & 13,10 & Média \\
Cerrado & 1.579 & 10,57 & Alta \\
Campo limpo/solo úmido & 363 & 2,43 & Muito baia \\
Rodovia GO 2010 & 98 & 0,66 & Alta \\
Rodovia BR 452 & 67 & 0,45 & Alta \\
Represa & 14 & 0,09 & Alta \\
Ferrovia Norte-Sul & 13 & 0,08 & Alta \\
Granjas & 8 & 0,05 & Alta \\
\hline Área total & 14935 & 100 & - \\
\hline
\end{tabular}

Fonte: Adaptado de Kawakubo et al. (2005) e Ross (1994). 
Figura 5 - Uso da terra e cobertura vegetal na bacia hidrográfica do ribeirão Douradinho,

Sudoeste de Goiás

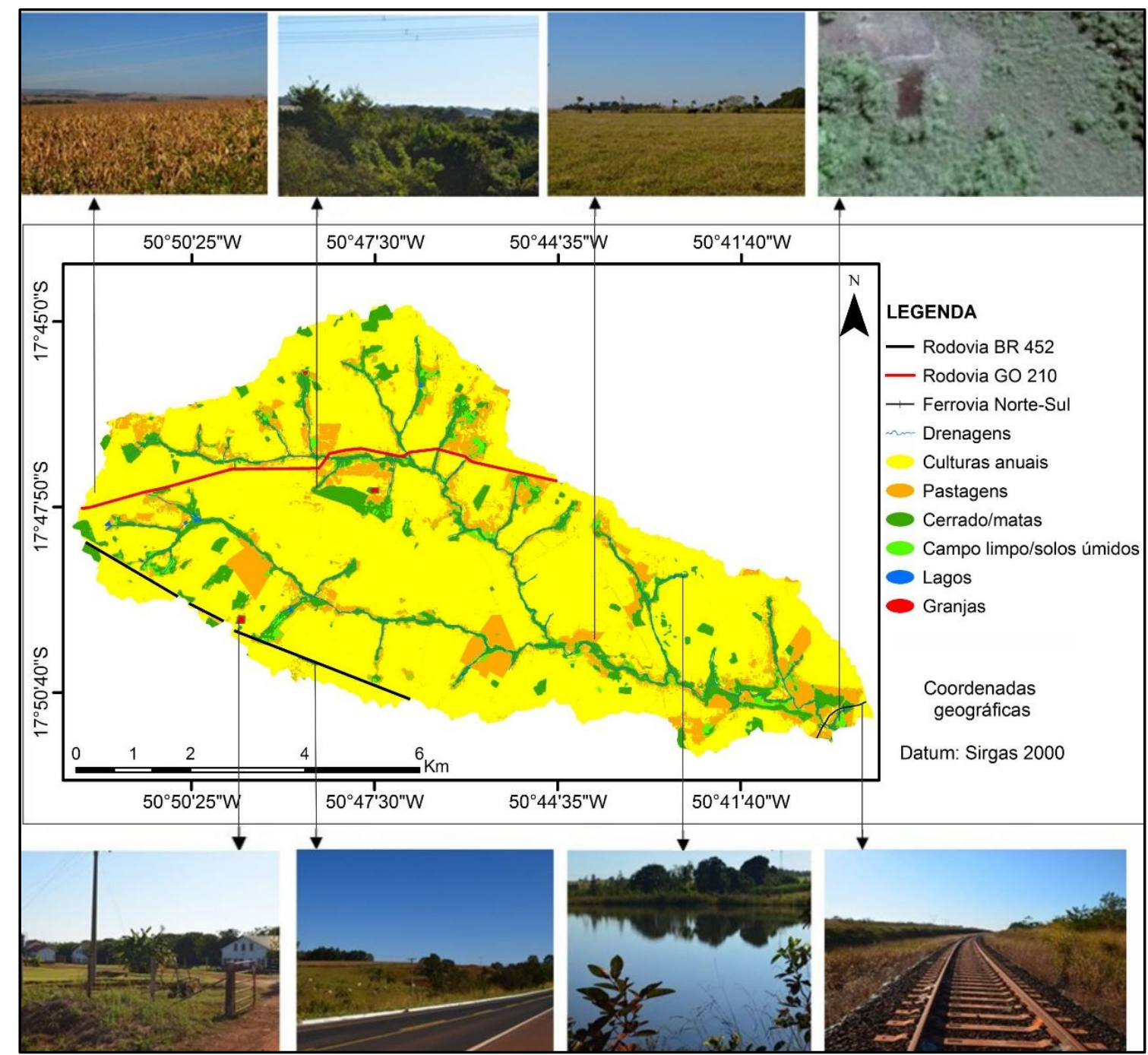

Fonte: Elaborado pelos autores.

Tratando-se da fragilidade potencial, predomina na área de estudo a fragilidade potencial baixa $(71,32 \%)$, seguida da fragilidade potencial muito baixa $(28,68 \%)$, não ocorrendo a fragilidade potencial média, alta e muito alto (Tabela 4; Figura 6). Os níveis baixos de fragilidade potencial é em decorrência da maior área com baixa declividade (Tabela 1; Figura 2) e Latossolos, considerados de baixa fragilidade ambiental (Tabela 2; Figura 3).

Tabela 4 - Classes de fragilidade potencial na bacia hidrográfica do ribeirão Douradinho, Sudoeste de Goiás

\begin{tabular}{ccc}
\hline Fragilidade & Ha & $\%$ \\
\hline Muito baixa & 4.284 & 28,68 \\
Baixa & 10.651 & 71,32 \\
\hline Total & 14.935 & 100 \\
\hline
\end{tabular}

Fonte: Elaborado pelos autores. 


\begin{tabular}{|c|c|c|}
\hline & $\begin{array}{c}\text { GEOAMBIENTE ON-LINE } \\
\text { Revista Eletrônica do Curso de Geografia - UFG/REJ } \\
\text { Graduação e Pós-Graduação em Geografia } \\
\text { http://revistas.ufg.br/index.php/geoambiente/index } \\
\text { Apoio: PRPG/PROAPUPEC }\end{array}$ & 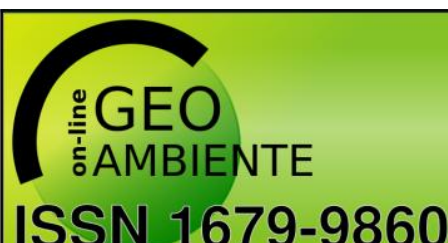 \\
\hline & Jataí-GO | n 29 | Jul-Dez & \\
\hline
\end{tabular}

Figura 6 - Fragilidade potencial na bacia hidrográfica do ribeirão Douradinho, Sudoeste de

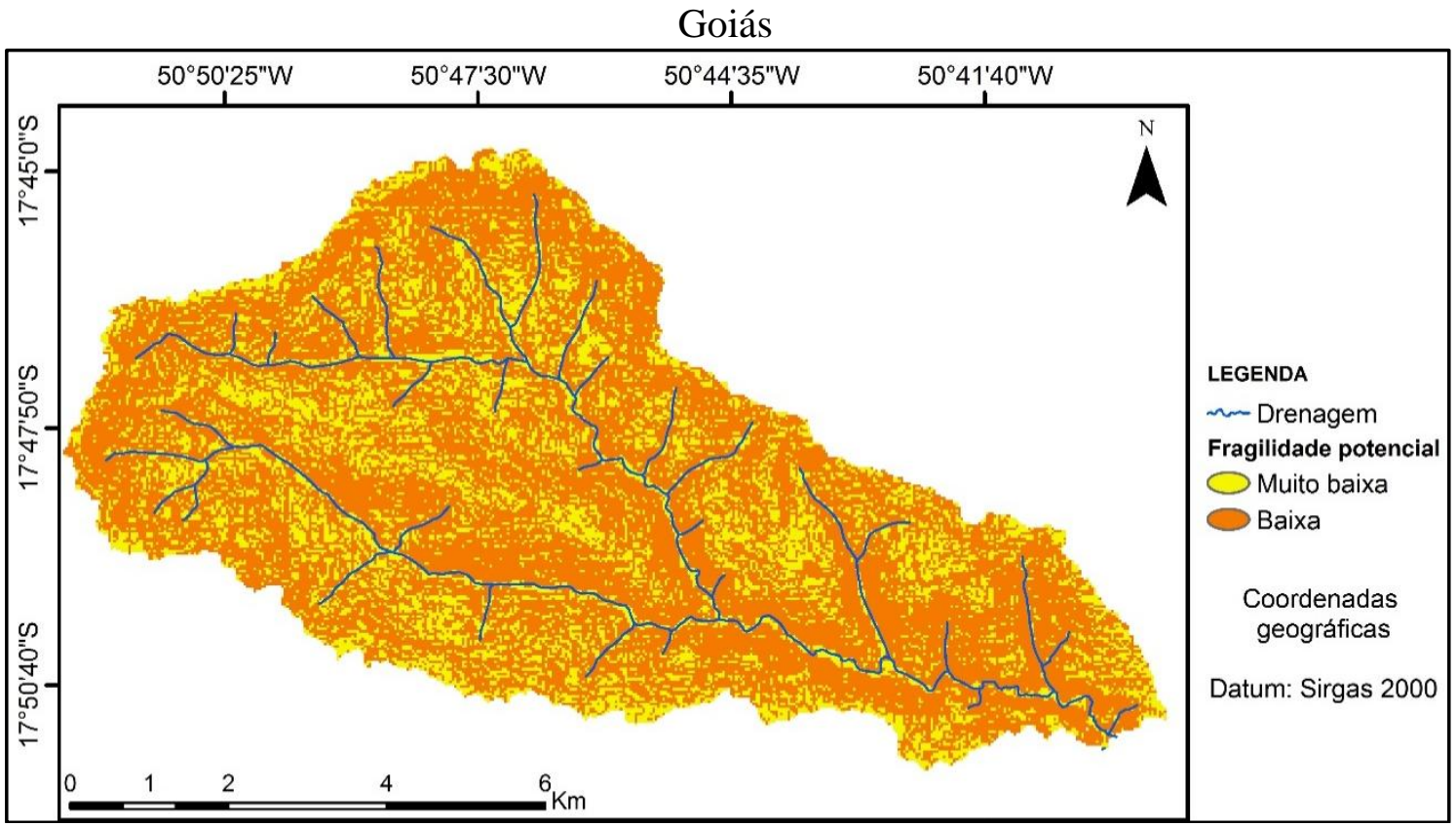

Fonte: Elaborado pelos autores.

Quanto a fragilidade emergente, verificou-se o predomínio dos níveis de fragilidade emergente média $(54,38 \%)$, seguida de fragilidade emergente baixa $(42,42 \%)$ e fragilidade emergente muito baixa (3,19\%),não sendo verificadas as classes de fragilidade emergente alta e muito alta(Tabela 5; Figura 7).

O destaque para a classe de fragilidade emergente média na bacia hidrográfica é em decorrência das formas de uso da terra e cobertura vegetal ser predominantemente de culturas anuais (principalmente soja e milho) e pastagem, que, ao serem implantadas de forma a retirar coberturas vegetais naturais, aumentam a possibilidade de erosões e outros impactos ambientais negativos, que afetam diretamente os níveis de fragilidade emergente, conforme Ross (1994).

Portanto, a fragilidade ambiental na bacia do ribeirão Douradinho (GO) é caracterizada por uma fragilidade potencial baixa, sendo explicada por seus fatores físicos (declividades com predominância de fragilidade muito baixa e fragilidade baixa e solos com fragilidade muito baixa); e uma fragilidade emergente média, sendo esta ocasionada, principalmente, pelas formas de utilização das terras, que se encontram cobertas predominantemente por culturas agrícolas e pastagens. 


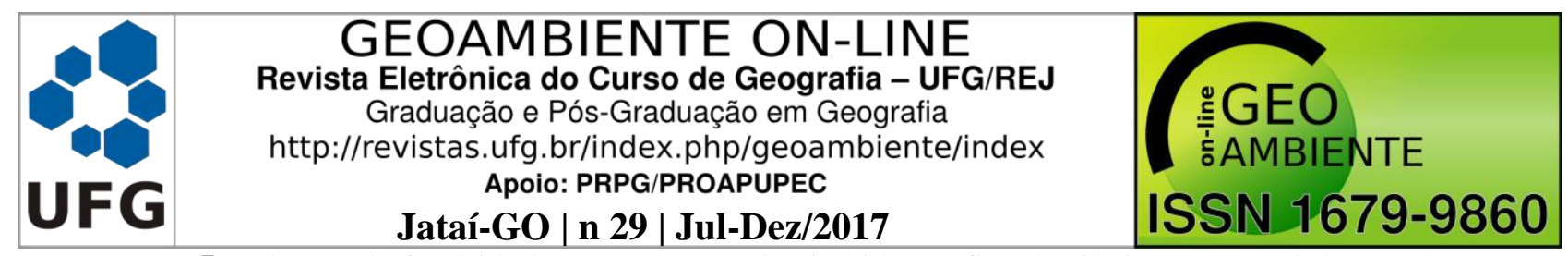

Tabela 5 - Classes de fragilidade emergente na bacia hidrográfica do ribeirão Douradinho, Sudoeste

\begin{tabular}{ccc}
\multicolumn{3}{c}{ de Goiás } \\
\hline Fragilidade & $\mathrm{km}^{2}$ & $\%$ \\
\hline Muito baixa & 477 & 3,19 \\
Baixa & 6.336 & 42,42 \\
Média & 8.122 & 54,38 \\
\hline Total & 14.935 & 100 \\
\hline
\end{tabular}

Fonte: Elaborado pelos autores.

Figura 7 - Fragilidade emergente da bacia hidrográfica do ribeirão Douradinho, Sudoeste de

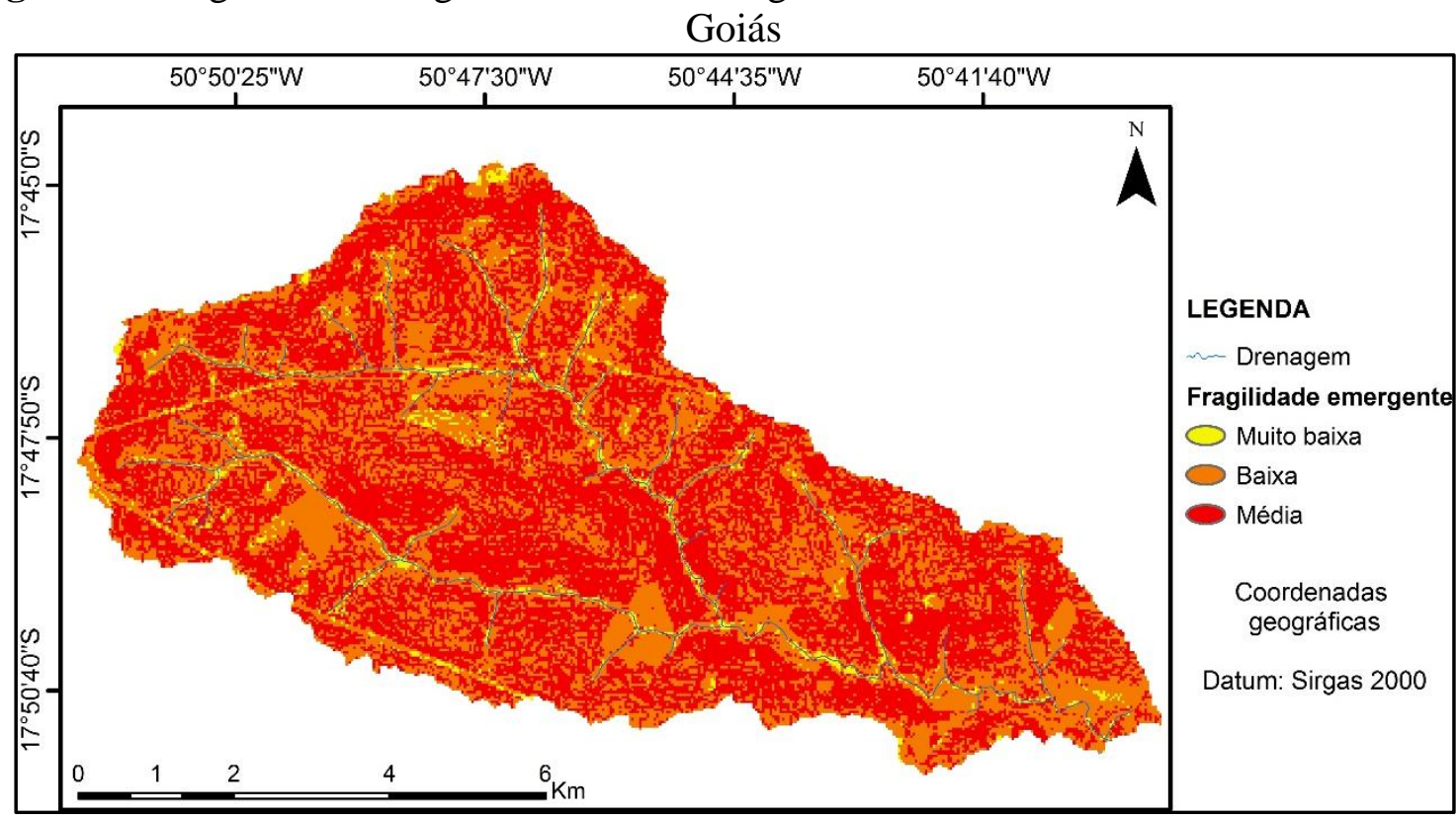

Fonte: Elaborado pelos autores.

Foram observadas ocorrências de erosão laminar na área de fragilidade emergente média, causando a perda de solos e, consequentemente, prejuízos ambientais e econômicos, indicando que nessa categoria é preciso que o manejo seja realizado considerando as técnicas conservacionistas e legislação ambiental vigente.

A erosão observada na área de estudo ocorre em área de pastagem degradada. A degradação dessa pastagem pode ser afirmada que é em decorrência da área apresentar, além da fragilidade ambiental emergente média, fatores favoráveis ao processo de degradação, como ausência de camaleões em curva de nível.

Conforme Zimmeret al., (2012), a área de pastagem, em monocultivo, em solos de baixa fertilidade e com manejo inadequado, apresenta grande risco para a pecuária nacional, principalmente com o acelerado processo de degradação dessas pastagens.

Segundo Zimmeret al. (2012), os principais fatores envolvidos no processo de degradação de pastagem, em ordem de importância, na maioria dos casos são: excesso de 

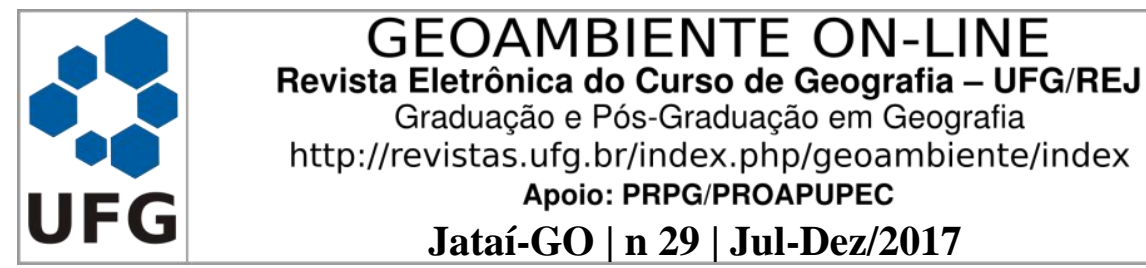

GEOAMBIENTE ON-LINE

Eletrônica do Curso de Geografia - UFG/REJ

Graduação e Pós-Graduação em Geografia

lotação (unidade animal/unidade de área) e manejo inadequado das pastagens; falta de correção e adubação na formação e, principalmente, falta de reposição de nutrientes pela adubação de manutenção; uso de espécie ou cultivar inadequada, não adaptada ao clima, solo e objetivo da produção; técnicas de preparo de solo e de semeadura impróprias; ausência de práticas conservacionistas do solo; e uso de sementes de baixa qualidade e origem desconhecida.

Ocorrências de invasoras,pragas, doenças, compactação do solo e erosão, entre outros,muitas vezes são apontados como causadores da degradação, mas,na realidade, são consequências do não atendimento das premissas acima mencionadas(ZIMMER et al., 2012), ou seja, ausência de planejamento e gestão ambiental e agronômica tendo em vista a produção sustentável.

De acordo com Bacani (2015) processos erosivos normalmente são associados à agricultura. Embora na literatura serem apresentados diversos estudos que revelam impactos negativos significativos da agricultura, a mesma quando desenvolvida respeitando-se as práticas conservacionistas, como ocorre predominantemente na área agrícola da bacia hidrográfica do Alto Rio Coxim), localizada em São Gabriel do Oeste e Camapuã, situados na porção Centro-Norte do Estado de Mato Grosso do Sul, onde é verificado que a degradação por erosão é menor quando comparada à pecuária (BACANI, 2015).

\section{Conclusão}

- O estudo da fragilidade ambienta na bacia hidrográfica do ribeirão Douradinho possibilitou diagnosticar de forma integrada os graus de fragilidade ocasionados por fatores naturais (declividade, tipos de solo e precipitação) e por atividades antrópicas (uso da terra e a cobertura vegetal).

- Através dos resultados desse estudo, foram verificados níveis de fragilidade potencial muito baixa e baixa, em decorrência das características físicas: declividade que se encontra em maior área nas classes de 0-3\% e 3-8\%, correspondendo a um relevo plano e suave ondulado; e solos com fragilidade muito baixa. Observou-se erosividade média, conferida pela precipitação.

- Com relação à fragilidade emergente,foram constatadas maiores áreas na classe de média fragilidade, fator esse condicionado pelas formas de uso da terra caracterizada por extensas áreas de produção agrícola, como culturas anuais (principalmente produção de milho e soja), e pastagem, sendo que estas atividades contribuem na 


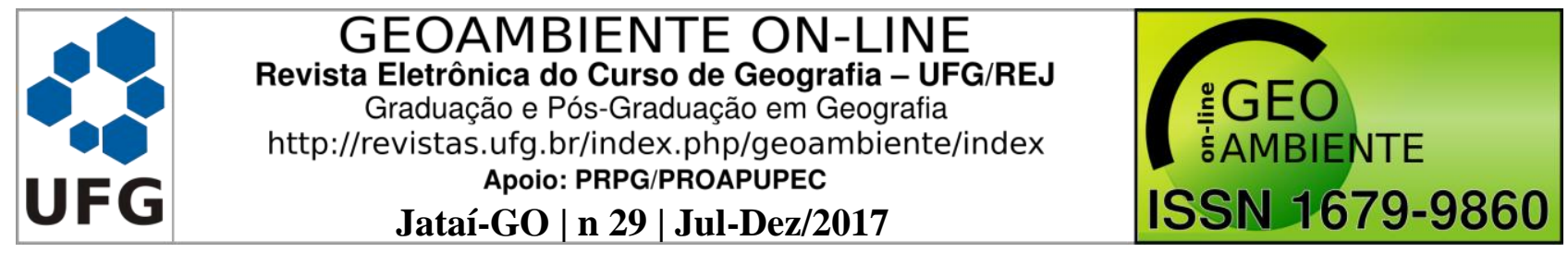

retirada de vegetações natural na área da bacia hidrográfica, deixando os solos suscetíveis à erosão laminar e eólica.

- Em decorrência da área com fragilidade emergente média, associadas a fatores favoráveis no processo de degradação, foram observadas áreas com erosão, causando perda de solos e, por conseguinte, prejuízos ambientais e econômicos, inferido a necessidade de planejamento e gestão ambiental na área de estudo.

- Este estudo irá subsidiar a gestão ambiental da bacia hidrográfica do ribeirão Douradinho, além de servir de base para outros trabalhos em outras regiões, melhorando a qualidade ambiental e promovendo a qualidade de vida

\section{Referências}

ALVES, W. S.; SCOPEL, I.; MARTINS, A. P.; MORAIS, W. A. Análise morfométrica da bacia do ribeirão das Abóboras - Rio Verde (GO). Geociências. v. 35, n. 4, p. 652-667, 2016. AYACH, L. R.; CUNHA, E. R.; SILVA, L. F.; BACANI, V. M. Utilização de imagens Google Earthpara mapeamento do uso e cobertura da terra da bacia hidrográfica do Córrego Indaiá, MS. Revista Geonorte, v.2, n.4, p.1801-1811, 2012.

BACANI, V. M., SAKAMOTO, A. Y., LUCHIARI, A., QUÉNOL, H.Sensoriamento remoto e SIG aplicados à avaliação da fragilidade ambiental de bacia hidrográfica. Mercator-Revista de Geografia da UFC, v. 14, n. 2, p. 119-135, 2015.

BDMEP - Banco de Dados Meteorológicos para Ensino e Pesquisa. Dados de precipitação de janeiro de 1996 a dezembro de 2016. Disponível em: <http://www.inmet.gov.br/projetos/rede/pesquisa/>. Acesso em: 13 de marçode 2017.

BERTONI, J. C.; LOMBARDI NETO, J. Conservação do solo. 5 ed. São Paulo: Icone, $2005.355 \mathrm{p}$.

BRASIL. Ministério do Planejamento, Orçamento e Gestão. Instituto Brasileiro de Geografia e Estatística - IBGE. Cidades. Disponível em: <http://cidades.ibge.gov.br/v3/cidades/homecidades>. Acesso em: 23 de junho de2017.

CABRAL, J. B. P., ROCHA, I. R., MARTINS, A. P., ASSUNÇÃO, H. F., BEGAT, V. A. Mapeamento da fragilidade ambiental da bacia hidrográfica do rio Doce (GO): utilizando técnicas de Geoprocessamento. Revista Geofocus, n. 11, p. 51-69, 2011.

CARVALHO, N.O. Hidrossedimentologia prática. Rio de Janeiro, CPRM - Companhia de Pesquisa em Recursos Minerais, 1994. p.372. 


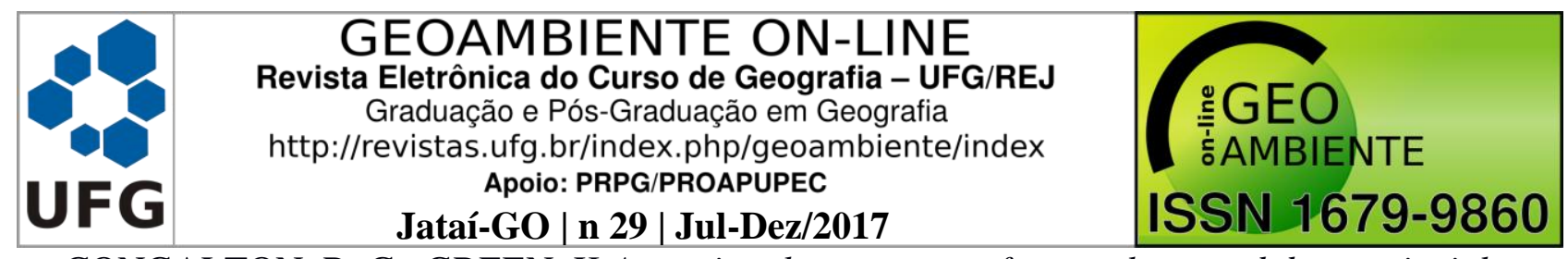

CONGALTON, R. G., GREEN, K.Assessing the accuracy of remotely sensed data: principles and practices. 2 ed. New York: Lewis Publishers, 2009. 137 p.

EMBRAPA - Empresa Brasileira de Pesquisa Agropecuária. Sistema Brasileiro de Classificação de Solos.3 ed. Editores Técnicos: Humberto Gonçalves dos Santos et al. Rio de Janeiro (RJ): Embrapa Solos, 2013. 353 p.

KAWAKUBO, F. S.; MORATO, R. G.; CAMPOS, K. C.; LUCHIARI, A.; ROSS, J. L. S. Caracterização empírica da fragilidade ambiental utilizando geoprocessamento. In.: Anais XII SIMPÓSIO BRASILEIRO DE SENSORIAMENTO REMOTO, 12, 2005, Goiânia, Brasil, INPE, p. 2203-2210, 2005.

LANDIS, R.; KOCH, G. G. "The measurement of observer agreement for categorical data", Revista Biometrics, v.33, n.1, p.159-174, 1977.

PEEL, M. C., FINLAYSON, B. L., MCMAHON, T. A. Updated world map of the KöppenGeiger climate classification. Hydrology Earth System Sciences, v. 11, p. 1633-1644, 2007. QUEIROZ JUNIOR, V. S; CABRAL, B. P; ROCHA, I. R; BARCELOS, A. A. N. Uso de geotecnologias na caracterização da fragilidade ambiental da Bacia da UHE Foz do Rio Claro (GO). GeoFocus, n. 15, p. 193-212,2015.

ROSA, R. Introdução ao sensoriamento remoto. 7. ed. Uberlândia: EDUFU, 2009. 264 p.

ROSS, J. L. S. “Análise empírica da fragilidade dos ambientes naturais e antropizados", Revista do Departamento de Geografia, São Paulo (SP), n.8. p.63-74, 1994.

SIEG. Sistema Estadual de Geoinformação do Estado de Goiás. Downloads/SIG-Shapefiles. Disponível em: <http://www.sieg.go.gov.br/> Acesso em: 01 de junho de2017.

SIMÕES, L. B.Integração entre um modelo de simulação hidrológica e sistema de informação geográfica na delimitação de zonas tampão ripárias. 2001. 187 f. Tese (Doutorado em Agronomia/Energia na Agricultura) - Faculdade de Ciências Agronômicas, Universidade Estadual Paulista, Botucatu (SP), 2001.

TAMANINI, M. S. A. Diagnóstico Físico-Ambiental para determinação da fragilidade potencial e emergente da Bacia do Baixo Curso do Rio Passaúna em Araucária - PR. $118 \mathrm{f}$. Dissertação (Mestrado em Geografia) - Setor de Ciências da Terra, Universidade Federal do Paraná, Curitiba (PR), 2008.

TRICART, J. Ecodinâmica. Rio de Janeiro: SUPREN e IBGE, 1977, 91 p.

USGS- United States Geological Survey. (2016): Earth Explorer. Disponível em: $<$ https://earthexplorer.usgs.gov/>. Acesso em: 20 de janeiro de2017. 


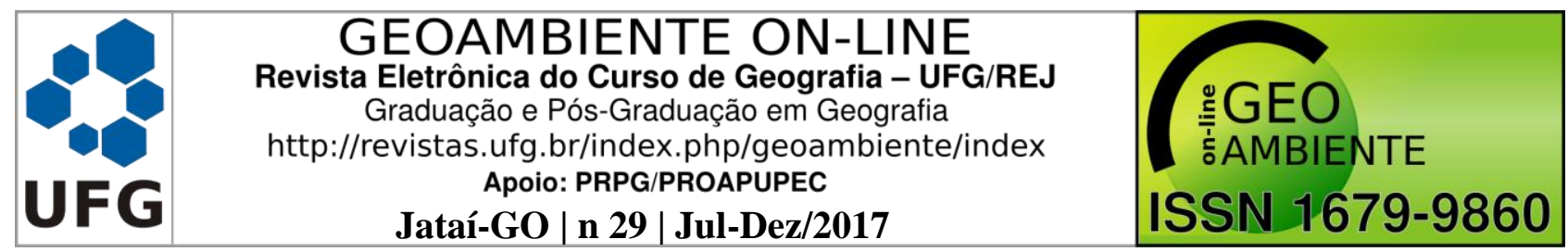

WISCHMEIER, W. H. E SMITH, D. D. Predicting rainfall erosion losses: a guide to conservation planning. Washington, United States Department of Agriculture. Agriculture Handbook, number 537, 1978. 58 p.

ZIMMER, A. H.; MACEDO, M. C. M.; KICHEL, A. N.; ALMEIDA, R. G. Degradação, recuperação e renovação de pastagens. Campo Grande (MS): Embrapa Gado de Corte, 2012. 46 p. Disponível em: <https://www.embrapa.br/busca-de-publicacoes//publicacao/951322/degradacao-recuperacao-e-renovacao-de-pastagens>. Acesso em: 24 de junho de2017. 